\title{
GCU
}

Glasgow Caledonian

University

University for the Common Good

\section{The prevalence of hepatitis C virus among people of South Asian origin in Glasgow: results from a community based survey and laboratory surveillance}

O'Leary, Maureen C.; Sarwar, Mohammed; Hutchinson, Sharon J.; Weir, Amanda; Schofield, Joe; McLeod, Allan; Cameron, Sheila; McTaggart, Christine; Banday, Shabir; Foster, Graham R.; Ahmed, S.; Fox, Ray; Mills, Peter R. ; Goldberg, David; Anderson, Eleanor

Published in:

Travel Medicine Infectious Diseases

DOI:

10.1016/j.tmaid.2013.08.001

Publication date:

2013

Document Version

Author accepted manuscript

Link to publication in ResearchOnline

Citation for published version (Harvard):

O'Leary, MC, Sarwar, M, Hutchinson, SJ, Weir, A, Schofield, J, McLeod, A, Cameron, S, McTaggart, C, Banday, S, Foster, GR, Ahmed, S, Fox, R, Mills, PR, Goldberg, D \& Anderson, E 2013, 'The prevalence of hepatitis C virus among people of South Asian origin in Glasgow: results from a community based survey and laboratory surveillance', Travel Medicine Infectious Diseases, vol. 11, no. 5, pp. 301-309.

https://doi.org/10.1016/j.tmaid.2013.08.001

\section{General rights}

Copyright and moral rights for the publications made accessible in the public portal are retained by the authors and/or other copyright owners and it is a condition of accessing publications that users recognise and abide by the legal requirements associated with these rights.

Take down policy

If you believe that this document breaches copyright please view our takedown policy at https://edshare.gcu.ac.uk/id/eprint/5179 for details of how to contact us. 


\section{Introduction}

Migrants to the UK from countries, such as Pakistan, with high prevalence rates of hepatitis $\mathrm{C}$ virus (HCV) may be more likely to be infected than the general UK population[1-2]. Those who are infected often acquire the virus in childhood and will carry the infection asymptomatically for many years, only being diagnosed when they show symptoms associated with advanced liver disease[3]. In the UK, those of South Asian origin are significantly more likely (up to nine times higher for those of Pakistani ethnicity) to be admitted to hospital with HCV-related end-stage liver disease, and die from this indication, than the Caucasian population[2].

To inform the development of targeted HCV testing and treatment services among South Asians, we first need to determine the prevalence of HCV infection among those living in the country. However, obtaining an accurate population-based prevalence estimate can be difficult. HCV surveillance data are confined to those who have presented for a diagnostic test either because they are symptomatic or they, or their clinician, perceive themselves to be at risk; thus the prevalence of infection among those who have been tested for HCV will tend to be higher than that in the overall population. Furthermore population-based surveys may be hampered by challenges associated with accessing the population and with getting them to engage with scientific research[4]. Uddin et al., the authors of the only previous HCV prevalence survey conducted among South Asians living in the UK (specifically England)[5], considered a range of recruitment methods but ultimately employed a named testing approach within community and religious centres to generate a representative sample.

In Scotland, 1\% of the five million population defines themselves as being of South Asian origin, with $60 \%$ being of Pakistani ethnicity, making them the largest minority ethnic group 
in the country[6]. No surveys have previously been conducted to determine their prevalence of HCV; consequently the burden of disease in this population is unknown.

We examined HCV prevalence data, in the Greater Glasgow and Clyde (GGC) Health Board area where over half of Scotland's South Asian population resides, from two sources: (i) a community-based survey and case finding initiative (hereafter known as the community based survey) similar to the screening study undertaken by Uddin et al.[5] and (ii) HCV laboratory surveillance data. Through examination and synthesis of HCV prevalence data from these two sources (a community-based sample of predominantly individuals who had never been tested for HCV and surveillance data on all individuals who had ever been tested for $\mathrm{HCV}$ ), we aimed to estimate the prevalence of HCV among those of South Asian origin, and to determine the extent of diagnosed/undiagnosed HCV infection in this population. In addition, using the community-based survey data, we compared the prevalence of HCV among first and second generation migrants of South Asian origin and identified risk-factors for infection in this population.

In addition, given the reported higher prevalence rates of hepatitis B virus (HBV) among South Asian migrants compared to the general population in the UK[7-9], we estimated the prevalence of HBV infection among participants in the community-based survey.

These data will inform whether case finding in the South Asian population, or its subgroups, is warranted. 


\section{Materials and Methods}

\section{Community-based survey}

Participants were recruited from six mosques and four community centres serving the South Asian community in the GGC area between December 2009 and August 2010. Selection of mosques and community centres was based on their ability to accommodate testing on or close to their premises. All persons aged 18 years or older attending Friday prayers at the mosques and attending the community centres on survey days were invited to participate. Posters and announcements in the local media serving the South Asian community were used to disseminate information about the survey and testing sessions to our target population. Announcements were also made in the mosques in the run-up to survey days, and those attending mosques were invited to inform family members and other household contacts about the survey and that they could also participate and be tested.

Individuals were given the option to participate and be tested for both HCV and HBV infection on either a named or anonymous basis. Thus, individuals who did not wish to receive their test results for any reason (e.g. they had previously been tested) were encouraged to participate and get tested in an anonymous manner, in order to minimise potential bias generated by a self-selected group coming forward for named testing. Informed written consent was obtained from all participants by trained Urdu speaking fieldworkers, who also collected demographic and risk factor data for each participant using a standardised questionnaire. Nurses were employed to take dried blood spot (DBS) samples from participants. Those who participated on a named basis were notified of the result of their HCV and HBV test, and, where appropriate, were invited to attend a local specialist centre for confirmatory blood testing and further management and treatment. We obtained ethical approval for this study from the Glasgow West Research Ethics Committee. 
DBS samples were tested for HCV and HBV at the West of Scotland Specialist Virology Centre. Samples were eluted and tested for HCV antibody using a modified protocol for the Ortho HCV 3.0 SAVe ELISA (product number 940982, Ortho Diagnostics, Amersham)[10]. This assay has a sensitivity of $100 \%(95 \% \mathrm{Cl}: 98-100 \%)$ and a specificity of $100 \%(95 \% \mathrm{Cl}$ : $99-$ $100 \%)$ in low prevalence populations[10]. All reactive samples were repeat tested using the same assay, and those confirmed were tested for HCV RNA using PCR. DBS samples were tested for HBV core antibodies (anti-HBc) and HBV surface antigen ( $\mathrm{HBsAg}$ ) using the Abbott Architect automated platform. Confirmatory HCV and HBV tests on follow-up blood samples (for those found to be $\mathrm{HCV}$ antibody positive and those $\mathrm{HBsAg}$ positive on DBS) were undertaken according to routine laboratory procedures.

\section{Laboratory surveillance data}

The West of Scotland Specialist Virology Centre provides data to Health Protection Scotland (HPS) on all HCV antibody tests performed in the GGC Health Board area for surveillance purposes; data for the period $1^{\text {st }}$ January 1993 to $31^{\text {st }}$ December 2009 were available for this analysis. Data provided to HPS includes patient identifiers (forename and surname, date of birth, gender and a hospital/clinic number or community health index $(\mathrm{CHI})$ number (a unique identifier issued in Scotland to all those registered with the National Health Service), information on source of referral (here categorised as general practitioner (GP), hospital, routine screen or other) and test information (specimen date and HCV antibody result).

The computer programme Nam Pehchan[11] was applied to the names (surnames and forenames) recorded on the HCV test database, using a process described in detail elsewhere[12], to identify those of South Asian ethnic origin. This approach, reported to have a sensitivity in excess of $90 \%[12]$, has been previously applied to HCV laboratory 
surveillance data in England and Wales[13]. Using the names of those who participated in the community-based survey (above) as corroboration, we established that the software appropriately assigned a high proportion (96\%) of respondents as South Asian.

Once the Nam Pehchan software was applied to the HCV test records, full names were removed and forename initial and soundex of surname (a consonant-only phonetic encoding[14]) were retained, prior to analysis. Repeat or subsequent HCV test records for an individual were identified - on the basis of a match on either (i) sex, date of birth, forename initial and surname soundex, (ii) sex, date of birth and hospital/clinic number, or (iii) $\mathrm{CHI}$ number - and removed from further analysis.

\section{Data Analysis}

First, we examined the proportion who tested HCV antibody positive (i.e. prevalence of infection) in the two study populations: 1) individuals of South Asian origin who were tested for HCV antibodies in the community-based survey and in GGC during 2009-2010, and 2) individuals who had had a diagnostic HCV antibody test in GGC during 1993-2009 and who were assigned as South Asian according to Nam Pechan. For each population, we generated the prevalence of infection (and 95\% confidence interval (CI)) for all those tested for HCV antibodies, and stratified according to demographic characteristics and risk factors. Further, we conducted univariable and multivariable logistic regression analyses to determine the factors significantly associated with the prevalence of $\mathrm{HCV}$ infection in these two study populations. We analysed data using $\mathrm{R}[15]$.

We then generated an estimate of the overall prevalence of HCV infection among South Asians living in GGC during 2009, by combining information on: 
a) the size of the South Asian population living in GGC in 2009, stratified according to (i) those who had been previously tested for HCV infection, (ii) those who had not previously been tested for HCV and were born outside the UK, and (iii) those who had not previously been tested for HCV and were born in the UK; and

b) the prevalence of HCV infection in these South Asian sub-populations (i)-(iii).

For a), the size of the South Asian population living in GGC aged $\geq 18$ years was estimated based on the number of individuals of Asian/Asian British ethnicity (excluding Chinese) living in Scotland for $2009(\mathrm{~N}=82,500)$ as reported in the Annual Population Survey[16], adjusted for the proportion of South Asians residing in GGC (53\%) and aged $\geq 18$ years (65\%) based on the Scottish 2001 Census[6]. This estimated population was then stratified according to those who had ever/never been tested for HCV, based on the number of individuals who had ever been tested for HCV in GGC during 1993-2009 from the HCV laboratory surveillance data, and who were not known to have died before 2009 (7\%) according to linked mortality data. The estimated population of South Asians who had never been tested for HCV was further stratified according to those born in and outside the UK, based on the Scottish 2001 Census[6].

For b), the prevalence of HCV in the South Asian sub-populations was derived based on the laboratory HCV surveillance data for those who had ever been tested for HCV (and were not known to have died from the linked mortality data), and the community-based survey data for those who had never been tested for HCV and were either born in or outside the UK. Due to the relatively small number of UK-born South Asians who were recruited to the community-based survey in GGC, we generated an estimate of the prevalence of HCV among this sub-population by combining data from the survey conducted in GGC (where one out of 168 UK-born South Asians was found to be HCV infected, see Table 1) with that from a larger 
community-based survey undertaken in England[5] (where two out of 452 UK-born South Asians were found to be HCV infected). 


\section{Results}

\section{Community-based survey}

Characteristics of participants

A total of 1,288 individuals participated, completed a questionnaire and provided a DBS sample for HCV and HBV testing; all participants requested to have their test results returned to them, and thus no-one took part anonymously. Almost two-thirds (833/1288) of participants were recruited from mosques and the rest from community centres. Based on estimates of the total number of people attending recruitment venues on survey days, approximately $25 \%$ of those attending mosques and $40 \%$ of those attending community centres participated. All participants were of South Asian origin.

The majority of participants were male (63\%), aged $30-69$ years $(69 \%)$ and born outside the UK (87\%; with $79 \%$ of these born in Pakistan) (Table 1). Fourteen percent of participants reported that a family member was infected with HCV. Eleven percent of participants had had surgery in South Asia, and a further $36 \%$ reported having had either medical/dental treatment or an injection in South Asia.

Ten percent (127/1288) of participants reported having previously been tested for HCV; of these, $9 \%(11 / 127)$ reported a positive diagnosis (equating to $0.9 \%$ of all respondents). Four percent $(46 / 1288)$ of respondents reported a history of liver disease (with 15 reporting viral hepatitis, 5 jaundice, 4 liver abscesses, 1 cirrhosis and 21 unknown or unspecified liver disease). 


\section{Prevalence of $\mathrm{HCV}$}

Among all participants, $34(2.6 \%, 95 \% \mathrm{Cl}: 1.9-3.7)$ were found to be $\mathrm{HCV}$ antibody positive on DBS (Table 1), and 62\% (21/34) of these were also found to be HCV RNA positive (representing $1.6 \%$ of all participants). Among the eleven participants who reported that they had been previously diagnosed with $\mathrm{HCV}$, ten (91\%) tested HCV antibody positive on DBS. Thus, $71 \%(24 / 34)$ of HCV antibody positive cases detected in the survey/case-finding initiative were among individuals who were previously undiagnosed. The prevalence of HCV antibodies ranged from $0.6 \%(1 / 168)$ among those born in the UK to $3.1 \%(27 / 882)$ among those born in Pakistan $(p=0.07)$.

The odds of testing HCV antibody positive were significantly raised among participants aged 30 to 49 years compared with those aged 18 to 29 years (adjusted odds ratio (aOR) 4.1; 95\% $\mathrm{Cl}$ : 1.0-17.2), and participants reporting having received surgery in South Asia (5.0; $95 \% \mathrm{Cl}$ : 2.0-12.3) and either medical/dental treatment or an injection in South Asia (2.2; 95\% Cl: 1.0-5.0) compared with those who had not reported receiving any of these treatments in South Asia (Table 1).

\section{Prevalence of $H B V$}

Among all participants, $44(3.4 \%, 95 \% \mathrm{Cl}$ : 2.6-4.6) were found to be anti-HBc positive on DBS. Of these, $27 \%(12 / 44)$ were also found to be HBsAg reactive (representing $0.9 \%$ of all participants), and none tested HBV IgM antibody positive. HBsAg reactivity was not significantly associated with age, sex, country of birth or with medical-related treatments received in South Asia (data available from authors on request). One individual was coinfected with both $\mathrm{HBV}$ and $\mathrm{HCV}$, testing both anti-HBc, $\mathrm{HBsAg}$ reactive and $\mathrm{HCV}$ antibody and HCV RNA positive. 
Follow-up of cases

Of the 21 participants found to be HCV RNA positive on DBS, 19 (90\%) attended a specialist centre for confirmatory blood testing; the majority of these (14/17: $82 \%)$ were infected with HCV genotype 3. Of the nineteen patients who attended a specialist centre, 15 (79\%) continued to attend for follow-up treatment and care; of the remaining four patients, three returned to Pakistan and one person died during follow-up. Of those who attended for follow-up treatment and care, eight (53\%) were initiated on HCV antiviral therapy within 18 months of their diagnosis. Of the seven who were not yet initiated on therapy, one had previously been treated and two had contraindications.

Of the twelve participants found to be $\mathrm{HBsAg}$ positive on DBS, seven (58\%) attended a specialist centre for confirmatory blood tests. Of these, five (71\%) attended for follow-up treatment and care and one was subsequently initiated on HBV antiviral therapy within 18 months of diagnosis.

\section{Laboratory surveillance data}

Among individuals tested for HCV antibodies in the GGC area during 1993-2009, 6404 were assigned as being of South Asian origin using the Nam Pechan software. The majority of these individuals had been first tested for HCV antibodies during 2005-2009 (56\%) and a large proportion had been tested by a GP (44\%) (Table 2). Among those who had been tested for HCV antibodies during 1993-2009 and who were assigned as South Asian, the proportion found to be HCV antibody positive (at their first test) was 9.3\% (95\% Cl: $8.6-$ 10.1); this prevalence of diagnosed infection was similar to that reported among participants in the community-based survey who had previously been tested for HCV. 
The odds of testing HCV antibody positive among South Asians who had undergone a diagnostic HCV test were significantly raised among those aged 30 years or more compared with those aged 18 to 29 years (aORs for those aged 30-49 years: $1.6,95 \% \mathrm{Cl}: 1.3-2.0 ; 50-69$ years: $2.4,95 \% \mathrm{Cl}: 1.8-3.1$; and $70+$ years: $2.3,95 \% \mathrm{Cl}: 1.5-3.5)$. The odds of testing HCV antibody positive were significantly reduced among those who were first tested in 20002009 compared with those who first tested during 1993-2000 (aORs for those first tested in 2000-2004: 0.7, 95\% Cl: 0.6-1.0; and 2005-2009: 0.6, 95\% Cl: 0.5-0.8), and those referred for testing from a hospital setting (aOR $0.7,95 \% \mathrm{Cl}: 0.6-0.9$ ) or from a setting performing routine screens (such as fertility clinic, occupational health and renal clinic) (aOR $0.1,95 \% \mathrm{Cl}$ : 0.1-0.2) compared with those referred by a GP. No difference in HCV antibody positivity was found between males and females (Table 2).

\section{Overall prevalence of HCV infection among South Asians}

Based on data from the annual population survey[16] and the 2001 Scottish Census, we estimated that there were approximately 28,430 people aged $\geq 18$ years living in the GGC area during 2009, who were of South Asian origin (Figure 1). Of these 28,430 South Asian people living in GCC, we estimated that approximately (i) 5,900 (21\%) had previously been tested for HCV (based on the HCV laboratory surveillance data), (ii) 13,910 (49\%) had not previously been tested for HCV and were born outside the UK (based also on the 2001 Census[6]), and (iii) 8,320 (29\%) had not previously been tested for HCV and were born in the UK. For these three sub-populations, the prevalence of HCV was estimated to range from $0.5 \%$ among those born in the UK, to $2.0 \%$ among those born outside the UK (and who had not previously been tested for HCV) and 9.3\% among those who had previously been tested for HCV. Combining these data (on the size of the three South Asian sub-populations (i)-(iii) with the prevalence of HCV infection in each group) generated an overall estimate of 870 HCV infected South Asians aged $\geq 18$ years living in the GGC area during 2009, 
representing an overall prevalence of 3.1\% (Figure 1). Of these 870 estimated HCV infected South Asians, 330 (38\%) were estimated to have never been tested and diagnosed with HCV infection. 


\section{Discussion}

Given the previously reported increased risk of HCV related liver disease[2] among South Asians, obtaining accurate estimates of the prevalence of $\mathrm{HCV}$ in this population is important to inform on the targeting of case finding activities.

We analysed data from both a community-based HCV survey and laboratory surveillance data to gain insights into the prevalence of $\mathrm{HCV}$ among the South Asian community in Glasgow. Among participants in the community-based sample, we detected an overall HCV prevalence rate of $2.6 \%(95 \% \mathrm{Cl} 1.9-3.7 \%)$. This is higher than the $1.6 \%$ prevalence detected among respondents to a similar multicentre survey in England[5], but is similar to the $2.7 \%$ prevalence rate that they reported among those born in Pakistan. In the English survey, around half of the respondents were born in Pakistan, compared with almost seventy percent of respondents in our survey; this may partially explain our higher prevalence estimate of HCV. In our community-based sample, the prevalence of HCV among those born in Pakistan was 3.1\%, but we also detected a higher prevalence of $\mathrm{HCV}$ among those born in India (2.9\%), compared with the estimated $0.2 \%$ prevalence among those born in India reported by the English study. Those born in Pakistan and India were five times more likely to test HCV antibody positive than those born in the UK, among whom we detected a HCV prevalence of $0.6 \%$. The $0.6 \%$ prevalence estimate in UK born South Asians is similar to that reported by the English survey (0.4\%).The prevalence of chronic HCV infection among respondents to the community-based survey was $2.6 \%$, compared with an estimated i) $0.8 \%$ among the total Scottish population[17],ii) $0.1 \%$ among the Scottish population excluding people who inject drugs (Health Protection Scotland)and iii) $0.004 \%$ among repeat blood donors(Scottish National Blood Transfusion Service). Respondents to the community survey were also more likely to have chronic HBV infection (0.9\%) than the general UK population $(0.3-0.4 \%)[8,18-19]$. 
The acquisition of HCV in South Asia is linked to the widespread re-use of needles in the healthcare setting $[3,20]$ and the use of contaminated blood products[21]. Risk behaviours for the acquisition of HCV were common among participants in the Glasgow community sample, with almost half having received either medical/dental treatment, surgery or an injection in South Asia. Further we found a significantly increased risk of HCV infection (i.e. testing HCV antibody positive) among those who reported having received medical/dental treatment, surgery or an injection in South Asia, compared with no history of these. Our findings are consistent with those from similar studies undertaken in South Asia[3, 22] and highlight the need to educate those travelling to South Asia, of the risks associated with undertaking medical procedures in the region.

Compared to those aged 18 to 29 , there was an increased risk of testing HCV antibody positive with age for all those identified as being of South Asian origin on the laboratory surveillance database. Those referred for testing by their general practitioner were more likely to test positive than those referred for testing from hospital or routine sources. We observed a declining risk of testing HCV antibody positive among those who were first tested between 2000 and 2004 and 2005 and 2009, compared with those tested before 2000. This may reflect an increasing awareness of the risk of $\mathrm{HCV}$ in this population and among their health care providers over time, resulting in a corresponding increased uptake of testing among a wider cross-section of the community. Alternatively there may be a declining risk of infection among more recent non-UK born migrants from South Asia to the UK, a hypothesis supported by the observed increased risk of testing antibody positive in the older population. 
Neither of our sources of data is likely to be representative of the general South Asian population for a variety of reasons. Our community-based sample was conducted in mosques and community centres; those attending these venues may not be representative of the general South Asian population in Glasgow. Specifically, those born in South Asia may be over-represented; as these individuals are at greater risk of HCV infection than UK born South Asians. Furthermore, participation in the community-based survey was on a selfselected basis and so may have been influenced by the participants own perceived risk of infection with HCV. This is supported by the fact that only ten percent of respondents had previously been tested for $\mathrm{HCV}$, compared to over a fifth we estimated to have been tested in this population. The possible self-exclusion of those who thought they were not at risk may have resulted in an over-estimate of HCV prevalence in this population but similarly the self-exclusion of those who already knew they were infected would have resulted in an underestimate.

Given that those presenting for testing are more likely to do so either because they are symptomatic or are perceived to be at risk of infection, the $\mathrm{HCV}$ prevalence estimate derived from this source is possibly an overestimate of the prevalence in the general population. Despite the recognised limitations of the data from the above sources, we can gain some insight into the overall prevalence of HCV among South Asians living in Glasgow, by combining the data from both sources. In this way we estimate the HCV antibody prevalence among South Asians in Glasgow to be around 3\%; three times higher than the estimated prevalence among the total population in Scotland[17]. A recent systematic review [23], reported a HCV prevalence rate of 1 to $1.9 \%$ in India and $4.7 \%$ in Pakistan. Our derived estimate is therefore consistent with what would be expected in a South Asian population where the majority are of Pakistani origin, such as that in Glasgow. 
Among participants in the community-based survey, $90 \%$ of those who tested HCV RNA positive on DBS subsequently attended specialist services for confirmatory blood tests and $80 \%$ of those who attended for confirmatory testing attended for follow-up treatment and care. This contrasts with a reported $50 \%$ attendance at follow-up treatment among former injecting drug users identified during a recent case-finding initiative undertaken in primary care practices in Glasgow[24]. This provides encouraging evidence that targeted testing of South Asians, particularly those born outside the UK, is likely to be successful in reducing the burden of disease in this community.

Whereas initiatives to case-find and treat those infected with HCV in Scotland have focused on high-risk populations, in particular those with a history of injecting drugs, our results support recommendations by the UK National Institute for Clinical Excellence[25] to increase awareness and testing among those born or brought up in countries and areas with an intermediate or high prevalence of hepatitis, such as those born in South Asia. The most cost-effective way to do this requires further investigation. In addition, those travelling to South Asia should be advised that undergoing medical, dental and surgical treatment or receiving injections in the region may increase their risk of contracting HCV and HBV. 


\section{Acknowledgements}

We would like to thank the mosques and community centres who facilitated the conduct of the community-based survey; the nurses from the Glasgow Clinical Research Facility who assisted with the taking of dried blood spot specimens and the staff of the REACH community health project, who assisted with the organisation and implementation of the fieldwork. 


\section{References}

1. Ades AE,Parker S, Walker J,Cubitt WD, and Jones $\mathrm{R}, \mathrm{HCV}$ prevalence in pregnant women in the UK. Epidemiol Infect 2000; 125: p. 399-405.

2. Mann AG, Trotter CL,Balogun MA, and Ramsay ME, Hepatitis C in ethnic minority populations in England. J Viral Hepat 2008; 15: p. 421-6.

3. Ali SA,Donahue RM,Qureshi $\mathrm{H}$, and Vermund $\mathrm{SH}$, Hepatitis $B$ and hepatitis $C$ in Pakistan: prevalence and risk factors. Int J Infect Dis 2009; 13: p. 9-19.

4. Sheikh A,Halani L,Bhopal R,Netuveli G,Partridge MR,Car J, et al., Facilitating the recruitment of minority ethnic people into research: qualitative case study of South Asians and asthma. PLoS Med 2009; 6: p. e1000148.

5. Uddin G,Shoeb D,Solaiman S,Marley R,Gore C, Ramsay M, et al., Prevalence of chronic viral hepatitis in people of south Asian ethnicity living in England: the prevalence cannot necessarily be predicted from the prevalence in the country of origin. J Viral Hepat 2010; 17: p. 327-35.

6. Analysis of Ethnicity in the 2001 Census Summary Report. 2004; Available from: http://www.scotland.gov.uk/Resource/Doc/47210/0025543.pdf.

7. Boxall E,Skidmore S,Evans $C$, and Nightingale $S$, The prevalence of hepatitis $B$ and $C$ in an antenatal population of various ethnic origins. Epidemiol Infect 1994; 113: p. 523-8.

8. Hahne S,Ramsay M,Balogun K,Edmunds WJ, and Mortimer $\mathrm{P}$, Incidence and routes of transmission of hepatitis B virus in England and Wales, 1995-2000: implications for immunisation policy. J Clin Virol 2004; 29: p. 211-20. 
9. Soldan K,Gay NJ,Allain JP, Llewelyn C,Jones C, Reeves I, et al., The prevalence of hepatitis B infection in adults with no recognized increased risk of infection. J Infect 2000; 41: p. 198-9.

10. Judd A,Parry J,Hickman M,McDonald T,Jordan L,Lewis K, et al., Evaluation of a modified commercial assay in detecting antibody to hepatitis C virus in oral fluids and dried blood spots. J Med Virol 2003; 71: p. 49-55.

11. Neggers YH,Cutter GR,Alvarez JO,Goldenberg RL,Acton R,Go RC, et al., The relationship between maternal serum zinc levels during pregnancy and birthweight. Early Hum Dev 1991; 25: p. 75-85.

12. Cummins $\mathrm{C}$, Winter $\mathrm{H}$, Cheng $\mathrm{KK}$, Maric R,Silcocks $\mathrm{P}$, and Varghese $\mathrm{C}, \mathrm{An}$ assessment of the Nam Pehchan computer program for the identification of names of south Asian ethnic origin. J Public Health Med 1999; 21: p. 401-6.

13. Gungabissoon U,Balogun MA, and Ramsay ME, Hepatitis C virus: laboratory surveillance in England and Wales, 1992-2004. Epidemiol Infect 2007; 135: p. $541-8$

14. Mortimer JY and Salathiel JA, 'Soundex' codes of surnames provide confidentiality and accuracy in a national HIV database. Commun Dis Rep CDR Rev 1995; 5: p. R183-6.

15. R: A Language and Environment for Statistical Computing. 2011, $\mathrm{R}$ Development Core Team, R Foundation for Statistical Computing: Vienna.

16. Local Area Labour Markets in Scotland; Statistics from the Annual Population Survey 2009. 2010, Crown Publications. 
17. Hepatitis C Action Plan for Scotland. Phase II: May 2008-March 2011. 2008 [cited 200815 May]; Available from:

http://www.scotland.gov.uk/Publications/2008/05/13103055/0.

18. Gay NJ,Hesketh LM,Osborne KP,Farrington CP,Morgan-Capner P, and Miller E, The prevalence of hepatitis B infection in adults in England and Wales. Epidemiol Infect 1999; 122: p. 133-8.

19. Health Protection Agency. General Information on Hepatitis B. [cited 2012 18 October 2012]; Available from:

http://www.hpa.org.uk/Topics/InfectiousDiseases/InfectionsAZ/HepatitisB/G enerallnformationHepatitisB/hepbGenerallnfo/.

20. Hutin YJ,Hauri AM, and Armstrong GL, Use of injections in healthcare settings worldwide, 2000: literature review and regional estimates. BMJ 2003; 327: p. 1075.

21. Luby S,Khanani R,Zia M,Vellani Z,Ali M,Qureshi AH, et al., Evaluation of blood bank practices in Karachi, Pakistan, and the government's response. Health Policy Plan 2000; 15: p. 217-22.

22. Janjua NZ,Hamza HB,Islam M,Tirmizi SF,Siddiqui A,Jafri W, et al., Health care risk factors among women and personal behaviours among men explain the high prevalence of hepatitis C virus infection in Karachi, Pakistan. J Viral Hepat 2010; 17: p. 317-26.

23. Sievert W,Altraif I,Razavi HA,Abdo A,Ahmed EA,Alomair A, et al., A systematic review of hepatitis C virus epidemiology in Asia, Australia and Egypt. Liver Int 2011; 31 Suppl 2: p. 61-80. 
24. Cullen BL,Hutchinson SJ,Cameron SO,Anderson E,Ahmed S,Spence E, et al., Identifying former injecting drug users infected with hepatitis C: an evaluation of a general practice-based case-finding intervention. J Public Health (Oxf) 2012; 34: p. 14-23.

25. National Institute for Health and Clinical Excellence. Public Health Draft Guidance. Hepatitis B and C: ways to promote and offer testing to people at increased risk of infection. 
Table 1: Factors associated with HCV antibody prevalence in people of South Asian origin surveyed in Greater Glasgow and Clyde NHS Board during $2009-2010$.

\begin{tabular}{|c|c|c|c|c|c|c|c|c|c|c|c|c|c|c|c|}
\hline & & \multicolumn{2}{|c|}{ Total } & \multicolumn{4}{|c|}{ Prevalence of HCV Antibodies } & \multicolumn{4}{|c|}{ Univariate Analysis } & \multicolumn{4}{|c|}{ Multivariate Analysis } \\
\hline & & \multicolumn{2}{|r|}{$\%$} & \multicolumn{2}{|c|}{$n \quad \%$ of $N$} & \multicolumn{2}{|c|}{$95 \% \mathrm{Cl}$} & \multirow[t]{2}{*}{ OR } & \multicolumn{2}{|c|}{$95 \% \mathrm{Cl}$} & \multirow[t]{2}{*}{$p$} & \multirow[t]{2}{*}{ AOR } & \multicolumn{2}{|c|}{$95 \% \mathrm{Cl}$} & \multirow[t]{2}{*}{$p$} \\
\hline All & & 1288 & 100.0 & 34 & 2.6 & 1.9 & 3.7 & & & & & & & & \\
\hline \multirow[t]{4}{*}{ Age Group* } & $18-29$ & 256 & 19.9 & 2 & 0.8 & 0.2 & 2.8 & ref & & & & ref & & & \\
\hline & $30-49$ & 511 & 39.7 & 17 & 3.3 & 2.1 & 5.3 & 4.1 & 1.0 & 17.1 & 0.056 & 4.1 & 1.0 & 17.2 & 0.056 \\
\hline & $50-69$ & 375 & 29.1 & 9 & 2.4 & 1.3 & 4.5 & & & & & & & & \\
\hline & $70+$ & 146 & 11.3 & 6 & 4.1 & 1.9 & 8.7 & & & & & & & & \\
\hline \multirow[t]{2}{*}{ Gender } & Female & 474 & 36.8 & 10 & 2.1 & 1.1 & 3.8 & ref & & & & & & & \\
\hline & Male & 814 & 63.2 & 24 & 2.9 & 2.0 & 4.3 & 1.4 & 0.7 & 3.0 & 0.367 & & & & \\
\hline \multirow[t]{4}{*}{ Country of Birth** } & UK & 168 & 13.0 & 1 & 0.6 & 0.0 & 3.3 & ref & & & & & & & \\
\hline & Pakistan & 882 & 68.5 & 27 & 3.1 & 2.1 & 4.4 & 5.1 & 0.7 & 37.3 & 0.111 & & & & \\
\hline & India & 137 & 10.6 & 4 & 2.9 & 1.1 & 7.3 & & & & & & & & \\
\hline & Other & 101 & 7.8 & 2 & 2.0 & 0.5 & 6.9 & & & & & & & & \\
\hline Recruitment Setting & Mosque & 833 & 64.7 & 23 & 2.8 & 1.8 & 4.1 & ref & & & & & & & \\
\hline & Community Centre & 455 & 35.3 & 11 & 2.4 & 1.4 & 4.3 & 0.9 & 0.4 & 1.8 & 0.713 & & & & \\
\hline Deprivation Quintile & Least Deprived & 150 & 11.6 & 6 & 4.0 & 1.8 & 8.5 & ref & & & & & & & \\
\hline & 2 & 181 & 14.1 & 2 & 1.1 & 0.3 & 3.9 & 0.3 & 0.1 & 1.3 & 0.110 & & & & \\
\hline & 3 & 195 & 15.1 & 4 & 2.1 & 0.8 & 5.2 & 0.5 & 0.1 & 1.8 & 0.294 & & & & \\
\hline & 4 & 350 & 27.2 & 11 & 3.1 & 1.8 & 5.5 & 0.8 & 0.3 & 2.1 & 0.629 & & & & \\
\hline & Most Deprived & 292 & 22.7 & 7 & 2.4 & 1.2 & 4.9 & 0.6 & 0.2 & 1.8 & 0.350 & & & & \\
\hline & Not Known & 120 & 9.3 & 4 & 3.3 & 1.3 & 8.3 & 0.8 & 0.2 & 3.0 & 0.774 & & & & \\
\hline Member of family & No & 989 & 76.8 & 28 & 2.8 & 2.0 & 4.1 & ref & & & & & & & \\
\hline infected with HCV & Yes & 183 & 14.2 & 5 & 2.7 & 1.2 & 6.2 & 1.0 & 0.4 & 2.5 & 0.941 & & & & \\
\hline & Not Known & 116 & 9.0 & 1 & 0.9 & 0.0 & 4.7 & 0.3 & 0.0 & 2.2 & 0.237 & & & & \\
\hline Diabetes & No & 1045 & 81.1 & 25 & 2.4 & 1.7 & 3.5 & ref & & & & & & & \\
\hline & Yes & 221 & 17.2 & 8 & 3.6 & 1.8 & 7.0 & 1.5 & 0.7 & 3.4 & 0.302 & & & & \\
\hline & Not Known & 22 & 1.7 & 1 & 4.5 & 0.2 & 21.8 & 1.9 & 0.3 & 15.0 & 0.524 & & & & \\
\hline Travelled in south & & & & & & & & & & & & & & & \\
\hline Asia (SA) & No/Not Known & 59 & 4.6 & 1 & 1.7 & 0.1 & 9.0 & ref & & & & & & & \\
\hline (1 Not Known) & Yes & 1229 & 95.4 & 33 & 2.7 & 1.9 & 3.7 & 1.6 & 0.2 & 11.9 & 0.646 & & & & \\
\hline Surgery in SA & No/Not Known & 1144 & 88.8 & 24 & 2.1 & 1.4 & 3.1 & ref & & & & & & & \\
\hline (14 Not Known) & Yes & 144 & 11.2 & 10 & 6.9 & 3.8 & 12.3 & 3.5 & 1.6 & 7.4 & 0.001 & & & & \\
\hline Medical/Dental & & & & & & & & & & & & & & & \\
\hline Treatment in SA & No/Not Known & 831 & 64.5 & 15 & 1.8 & 1.1 & 3.0 & ref & & & & & & & \\
\hline (15 Not Known) & Yes & 457 & 35.5 & 19 & 4.2 & 2.7 & 6.4 & 2.4 & 1.2 & 4.7 & 0.014 & & & & \\
\hline Injection in SA & No & 990 & 76.9 & 18 & 1.8 & 1.2 & 2.9 & ref & & & & & & & \\
\hline & Yes & 219 & 17.0 & 11 & 5.0 & 2.8 & 8.8 & 2.9 & 1.3 & 6.1 & 0.007 & & & & \\
\hline & Not Known & 79 & 6.1 & 5 & 6.3 & 2.7 & 14.0 & 3.6 & 1.3 & 10.1 & 0.013 & & & & \\
\hline Surgery/Medical/ & No/Not Known & 687 & 53.3 & 10 & 1.5 & 0.8 & 2.7 & ref & & & & ref & & & \\
\hline $\mathrm{SA}^{* * *}$ & Surgery & 144 & 11.2 & 10 & 6.9 & 3.8 & 12.3 & 4.2 & 1.9 & 9.8 & $<0.001$ & 5.0 & 2.0 & 12.3 & $<0.001$ \\
\hline & $\begin{array}{l}\text { Medical/Dental/ Injection } \\
\text { but Not Surgery }\end{array}$ & 457 & 35.5 & 14 & 3.1 & 1.8 & 5.1 & 2.1 & 1.0 & 4.4 & 0.041 & 2.2 & 1.0 & 5.0 & 0.063 \\
\hline Blood Transfer in SA & No/Not Known & 1174 & 91.1 & 30 & 2.6 & 1.8 & 3.6 & ref & & & & & & & \\
\hline (30 Not Known) & Yes & 114 & 8.9 & 4 & 3.5 & 1.4 & 8.7 & 1.4 & 0.5 & 4.0 & 0.546 & & & & \\
\hline Street Barber in SA & No/Not Known & 753 & 58.5 & 18 & 2.4 & 1.5 & 3.7 & ref & & & & & & & \\
\hline (17 Not Known) & Yes & 535 & 41.5 & 16 & 3.0 & 1.8 & 4.8 & 1.3 & 0.6 & 2.5 & 0.509 & & & & \\
\hline Tattoo/Piercing in SA & No/Not Known & 1004 & 78.0 & 25 & 2.5 & 1.7 & 3.7 & ref & & & & & & & \\
\hline (16 Not Known) & Yes & 284 & 22.0 & 9 & 3.2 & 1.7 & 5.9 & 1.3 & 0.6 & 2.8 & 0.530 & & & & \\
\hline Vaccination in SA & No & 254 & 19.7 & 4 & 1.6 & 0.6 & 4.0 & ref & & & & & & & \\
\hline & Yes & 879 & 68.2 & 28 & 3.2 & 2.2 & 4.6 & 2.1 & 0.7 & 5.9 & 0.181 & & & & \\
\hline & Not Known & 155 & 12.0 & 2 & 1.3 & 0.4 & 4.6 & 0.8 & 0.1 & 4.5 & 0.817 & & & & \\
\hline
\end{tabular}

* In the univariate and multivariate analysis those aged $<30$ years old are compared with those aged 30 years and ** In the univariate analysis UK born is compared with non-UK born.

*** This variable combines three questions on surgery in south Asia (SA), medical/dental treatment in SA, and injec 
Table 2: Factors associated with HCV antibody prevalence in people of South Asian origin who had a diagnostic HCV test in Greater Glasgow and Clyde NHS Board during 1993-2009.

\begin{tabular}{|c|c|c|c|c|c|c|c|c|c|c|c|c|c|c|c|}
\hline \multirow{3}{*}{ All } & & \multicolumn{2}{|c|}{ Total } & \multicolumn{4}{|c|}{ Prevalence of HCV Antibody } & \multicolumn{4}{|c|}{ Univariate Analysis } & \multicolumn{4}{|c|}{ Multivariate Analysis } \\
\hline & & \multirow{2}{*}{$\frac{N}{6404}$} & \multirow{2}{*}{$\begin{array}{c}\% \\
100.0 \%\end{array}$} & \multirow{2}{*}{$\begin{array}{r}n \\
597\end{array}$} & \multirow{2}{*}{$\begin{array}{r}\% \text { of } \mathrm{N} \\
9.3\end{array}$} & \multicolumn{2}{|c|}{$95 \% \mathrm{Cl}$} & \multirow[t]{2}{*}{ OR } & \multicolumn{2}{|c|}{$95 \% \mathrm{Cl}$} & \multirow[t]{2}{*}{$p$} & \multirow[t]{2}{*}{ AOR } & \multicolumn{2}{|c|}{$95 \% \mathrm{Cl}$} & \multirow[t]{2}{*}{$p$} \\
\hline & & & & & & 8.6 & 10.1 & & & & & & & & \\
\hline \multirow[t]{5}{*}{ Age at first test } & $18-29$ & 1824 & $28.5 \%$ & 105 & 5.8 & 4.8 & 6.9 & ref & & & & ref & & & \\
\hline & $30-49$ & 3110 & $48.6 \%$ & 284 & 9.1 & 8.2 & 10.2 & 1.6 & 1.3 & 2.1 & $<0.001$ & 1.6 & 1.3 & 2.0 & $<0.001$ \\
\hline & $50-69$ & 1066 & $16.6 \%$ & 141 & 13.2 & 11.3 & 15.4 & 2.5 & 1.9 & 3.3 & $<0.001$ & 2.4 & 1.8 & 3.1 & $<0.001$ \\
\hline & $70+$ & 284 & $4.4 \%$ & 33 & 11.6 & 8.4 & 15.9 & 2.2 & 1.4 & 3.3 & $<0.001$ & 2.3 & 1.5 & 3.5 & $<0.001$ \\
\hline & Not Known & 120 & $1.9 \%$ & 34 & 28.3 & 21.0 & 37.0 & 6.5 & 4.2 & 10.1 & $<0.001$ & 6.0 & 3.7 & 9.5 & $<0.001$ \\
\hline \multirow[t]{3}{*}{ Gender } & Female & 2625 & $41.0 \%$ & 238 & 9.1 & 8.0 & 10.2 & ref & & & & ref & & & \\
\hline & Male & 3256 & $50.8 \%$ & 297 & 9.1 & 8.2 & 10.2 & 1.0 & 0.8 & 1.2 & 0.942 & 1.0 & 0.8 & 1.2 & 0.950 \\
\hline & Not Known & 523 & $8.2 \%$ & 62 & 11.9 & 9.4 & 14.9 & 1.3 & 1.0 & 1.8 & 0.048 & 1.3 & 0.9 & 1.7 & 0.112 \\
\hline \multirow[t]{3}{*}{ Year of first test } & $1993-2000$ & 903 & $14.1 \%$ & 128 & 14.2 & 12.1 & 16.6 & ref & & & & ref & & & \\
\hline & 2000-2004 & 1924 & $30.0 \%$ & 192 & 10.0 & 8.7 & 11.4 & 0.7 & 0.5 & 0.9 & 0.001 & 0.7 & 0.6 & 1.0 & 0.022 \\
\hline & 2005-2009 & 3577 & $55.9 \%$ & 277 & 7.7 & 6.9 & 8.7 & 0.5 & 0.4 & 0.6 & $<0.001$ & 0.6 & 0.5 & 0.8 & $<0.001$ \\
\hline \multirow[t]{4}{*}{ Referral Source* } & GP & 2790 & $43.6 \%$ & 326 & 11.7 & 10.5 & 12.9 & ref & & & & ref & & & \\
\hline & Hospital & 2055 & $32.1 \%$ & 223 & 10.9 & 9.6 & 12.3 & 0.9 & 0.8 & 1.1 & 0.366 & 0.7 & 0.6 & 0.9 & $<0.001$ \\
\hline & Routine & 1281 & $20.0 \%$ & 26 & 2.0 & 1.4 & 3.0 & 0.2 & 0.1 & 0.2 & $<0.001$ & 0.1 & 0.1 & 0.2 & $<0.001$ \\
\hline & Other & 278 & $4.3 \%$ & 22 & 7.9 & 5.3 & 11.7 & 0.6 & 0.4 & 1.0 & 0.061 & 0.7 & 0.4 & 1.0 & 0.078 \\
\hline
\end{tabular}

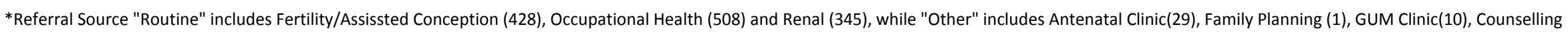
Clinic(100), Drug Service/Harm Reduction (7), Prison (5), Not Known (20) and Other Not Specified (106). 
Figure 1: Estimated prevalence of HCV antibodies (anti-HCV) among South Asians living in Greater Glasgow \& Clyde (GGC) during 2009.

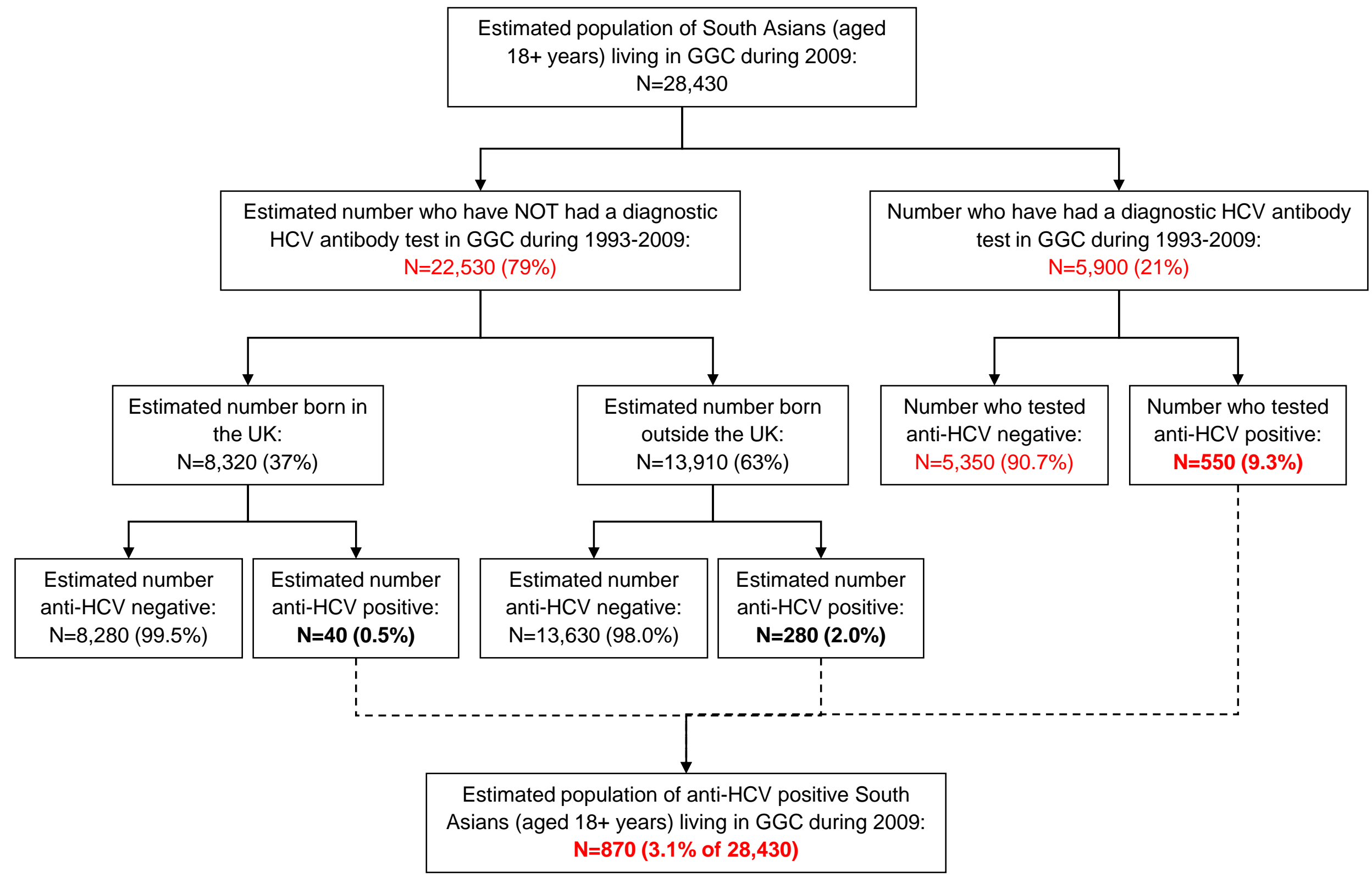

